\title{
MODEL PEMBELAJARAN ROLE PLAY DALAM MENINGKATKAN KEMAMPUAN BERMAIN DRAMA MAHASISWA JURUSAN SASTRA INGGRIS SEKOLAH TINGGI ILMU BAHASA ASING (STIBA) PERSADA BUNDA
}

\author{
Qori Islami Aris \\ Fakultas Ilmu Budaya, Universitas Lancang Kuning, Indonesia \\ qoriislamibintiaris@unilak.ac.id
}

Naskah diterima: 5 Desember ; direvisi: 12 Desember; disetujui: 19 Desember

\begin{abstract}
Abstrak
Mata kuliah drama jurusan sastra inggris Sekolah Tinggi Ilmu Bahasa Asing Persada Bunda hanya menitikberatkan pada analisis teks dan dialog. Sementara bermain drama juga dapat meningkatkan empat kemampuan yang harus dimiliki oleh mahasiswa sastra Inggris yaitu speaking skill, listening skill, reading skill, dan writing skill. Melalui speaking skill mahasiswa telah melakukan kegiatan berbicara. Sementara listening skill mahasiswa telah melakukan kegiatan menyimak. Pada saat membacakan penggalan dialog dalam naskah drama, mahasiswa melakukan kegiatan membaca dan tentu saja dibutuhkan reading skill yang mumpuni. Sementara pada writing skill mahasiswa diharapkan dapat menulis naskah teks drama yang ingin dipentaskan. Berdasarkan masalah ini, penulis tertarik untuk melakukan penelitian dengan judul "Model Pembelajaran Role Play dalam Meningkatkan Kemampuan Bermain Drama Mahasiswa Jurusan Sastra Inggris Sekolah Tinggi Ilmu Bahasa Asing (STIBA) Persada Bunda". Tujuan dilakukannya penelitian ini untuk melihat bagaimana model pembelajaran Role Play dapat meningkatkan kemampuan bermain drama. Berdasarkan data yang diperoleh, Penerapan model pembelajaran Role Play membantu meningkatkan kemampuan bermain drama mahasiswa jurusan sastra inggris Sekolah Tinggi Ilmu Bahasa Asing Persada Bunda dengan peningkatan Persentase Penilaian Hasil sebesar 29,20\%.
\end{abstract}

Kata Kunci : Role Play, Peningkatan Bermain Drama

\begin{abstract}
Drama course of English Literature of Foreign Language School Persada Bunda focuses on text analysis and dialogue. Playing the drama can also increase the four skills that must be possessed by students of English literature that is speaking skills, listening skills, reading skills, and writing skills. Through the speaking skills, students have been doing the talking activity. While listening skills, the student has been doing a listening activity. When reading a snippet of dialogue in a drama script, students do reading and of course, required a qualified reading skill. While the writing skill students are expected to write a drama text script to be staged. Based on this problem, the authors are interested in conducting research under the title "Role Play Learning Model in Enhancing the Ability to play Drama Students of English Literature of Foreign Language School of Foreign Studies (STIBA) Persada Bunda". The purpose of this research is to see how the Role Play learning
\end{abstract}


model can improve the ability to play drama. Based on the data obtained, Implementation of Role Play learning model helps to improve the ability to play drama majoring in English Literature of Foreign Language School Persada Bunda with an increase of the percentage of Result Assessment of $29.20 \%$.

Key Words: Role Play, Improved Drama Play

\section{Pendahuluan}

Drama berasal dari bahasa Yunani "dramoi" yang berarti berbuat, berlaku, bereaksi, bertindak. Pengertian lain tentang drama ialah kualitas komunikasi, situasi action, (segala yang terlihat dalam pentas/panggung) yang menimbulkan perhatian, kehebatan dan ketegangan pada penonton.

Drama juga dapat diartikan sebagai cerita konflik manusia dalam bentuk dialog yang diproyeksikan pada pentas dengan menggunakan percakapan dan gerak di depan penonton. Ajaran yang memperlajari masalah hukuh dan konvensi drama adalah dramaturgi.

Drama sebagai salah satu bentuk karya sastra bersifat imajinatif. Drama merupakan gambaran kehidupan yang dipentaskan di atas panggung yang menyajikan permasalahan-permasalahan yang pernah terjadi dan mungkin akan terjadi meskipun persoalan-persoalan kehidupan manusia yang dipentaskan itu hanyalah imajinatif.

Memerankan tokoh dalam drama, seorang aktor harus berangkat dari konsep bahwa drama merupakan gambaran cerita kehidupan sehari-hari. Kepandaian aktor menafsirkan hidup dan kehidupan secara pas, ekspresif dan estetik di atas panggung, membuat lakon drama menjadi aktual, mirip kehidupan manusia yang sebenarnya yang pernah dan mungkin akan dialami penonton. Rendra berpendapat bahwa, "Seorang aktor yang baik adalah yang bisa menjelmakan perannya dengan hidup sekali. Ia bisa menjelma menjadi seorang dokter dengan cara yang meyakinkan. Caranya memegang nadi pasien, caranya membalut luka, semuanya serba meyakinkan" ( 2007 : 09).
Bermain drama sebagai suatu proses kreatif memerankan tokoh kini dapat dilakukan di berbagai tempat. Diantaranya, kampus-kampus, sekolahsekolah, ekstrakurikuler, sanggar-sanggar seni, komunitas-komunitas dan banyak lagi.

Penulis melihat pada mata kuliah drama jurusan sastra inggris sekolah tinggi Persada Bunda hanya menitikberatkan pada analisis teks dan dialog. Sementara bermain drama juga dapat meningkatkan empat kemampuan yang harus dimiliki oleh mahasiswa sastra Inggris yaitu speaking skill, listening skill, reading skill, dan writing skill. Melalui speaking skill mahasiswa telah melakukan kegiatan berbicara. Sementara listening skill mahasiswa telah melakukan kegiatan menyimak. Pada saat membacakan penggalan dialog dalam naskah drama, mahasiswa melakukan kegiatan membaca dan tentu saja dibutuhkan reading skill yang mumpuni. Sementara pada writing skill mahasiswa diharapkan dapat menulis naskah teks drama yang ingin dipentaskan.

Berdasarkan latar belakang masalah di atas, penulis tertarik untuk melakukan penelitian dengan judul “Model Pembelajaran Role Play dalam Meningkatkan Kemampuan Bermain Drama Mahasiswa Jurusan Sastra Inggris Sekolah Tinggi Ilmu Bahasa Asing (STIBA) Persada Bunda".

Adapun rumusan masalah dalam penelitian, pertama bagaimanakah kemampuan bermain drama mahasiswa jurusan sastra inggris Sekolah Tinggi Ilmu Bahasa Asing Persada Bunda? Kedua bagaimanakah peningkatan kemampuan bermain drama mahasiswa jurusan sastra inggris Sekolah Tinggi Ilmu Bahasa Asing Persada Bunda? Dan bagaimanakah penggunaan model pembelajaran role 
play dalam meningkatkan kemampuan bermain drama mahasiswa jurusan sastra inggris Sekolah Tinggi Ilmu Bahasa Asing Persada Bunda?

Sedangkan tujuan yaitu Mengukur kemampuan bermain drama mahasiswa jurusan sastra inggris Sekolah Tinggi Ilmu Bahasa Asing Persada Bunda. Mengukur peningkatan kemampuan bermain drama mahasiswa jurusan sastra inggris Sekolah Tinggi Ilmu Bahasa Asing Persada Bunda dan Mengukur Sejauh mana penggunaan model pembelajaran role play dalam meningkatkan kemampuan bermain drama mahasiswa jurusan sastra inggris Sekolah Tinggi Ilmu Bahasa Asing Persada Bunda

Manfaat penelitian ini yaitu sebagai bahan informasi bagi sekolah untuk mengetahui daya kreatifitas sastra mahasiswa, sebagai bahan informasi bagi sekolah untuk mengetahui kemampuan bermain drama mahasiswa, sebagai bahan informasi bagi sekolah untuk mengetahui model pembelajaran Role Play dalam meningkatkan kemampuan bermain drama mahasiswa, sebagai pendorong mahasiswa dan pengajar agar sama-sama mempunyai minat dan kecintaan yang besar terhadap dunia sastra di Indonesia dan sebagai bahan masukan bagi teman-teman yang berminat mengadakan penelitian lebih lanjut terhadap materi ini.

\section{Tinjauan Pustaka}

\subsection{Model Pembelajaran Role Play}

Model pembelajaran merupakan upaya untuk menciptakan kondisi dengan sengaja agar tujuan pembelajaran dapat dipermudah (facilitated) pencapaiannya.

Dalam hal ini, model pembelajaran role play dilakukan agar tujuan pembelajaran nantinya dapat dipermudah pencapaiannya.

Sudrajat berpendapat bahwa: Model pembelajaran bermain peran (role play) adalah suatu cara penguasaan bahan-bahan pengajaran melalui pengembangan imajinasi dan penghayatan mahasiswa. Pengembangnya dan penghayatan mahasiswa dilakukan dengan memerankannya sebagai tokoh hidup atau benda mati. Permainan ini biasanya dilakukan lebih dari 1 orang, hal itu bergantung kepada apa yang diperankan.

Ia selanjutnya berpendapat lagi bahwa, "Bermain peran merupakan salah satu model pembelajaran yang diarahkan pada upaya pemecahan masalah yang berkaitan dengan hubungan antar manuia (interpersonal relationship), terutama yang menyangkut kehidupan peserta didik".

Sedangkan Uno (2007 : 25) berpendapat bahwa, Model ini, Pertama, dibuat berdasarkan asumsi bahwa sangatlah mungkin menciptakan analogi otentik ke dalam suatu situasi permasalahan kehidupan nyata. Kedua, bahwa bermain peran dapat mendorong mahasiswa mengekspresikan perasaannya dan bahkan melepaskan. Ketiga, bahwa proses psikologis melibatkan sikap, niali dan keyakinan (belief) kita serta mengarahkan pada kesadaran melalui keterlibatan spontan yang disertai analisis.

Selanjutnya Ashan (dalam Kurikulum Berbasis Kompetensi, 2003 : 173) berpendapat bahwa, "Role play; analisis kompetensi berdasrkan pengalaman dan penilaian terhadap sejumlah orang yang melakukan peran tertentu."

Dari beberapa pendapat di atas dapat disimpulkan bahwa melalui bermain peran (Role Play), peserta didik mencoba mengeksplorasi hubunganhubungan antar manusia dengan cara memperagakan dan mendiskusikannya, sehingga secara bersama-sama para peserta didik dapat mengeksporasi perasaan-perasaan, sikap-sikap, nilainilai, dan berbagai strategi pemecahan masalah.

Dalam aplikasinya, terdapat sembilam langkah model pembelajaran role play seperti yang telah dikemukakan oleh Uno (2007; 26), “(1) pemanasan (warming up); (2) memilih partisipan; (3) menyiapkan pengamat; (4) menata panggung; (5) memainkan peran; (6) diskusi dan evaluasi; (7) memainkan 
peran ulang; (8) diskusi dan evaluasi kedua; (9) berbagi pengalaman dan kesimpulan".

\subsection{Drama}

Dietrich (dalam Prasmadji, 1984 : 19) berpendapat, " drama adalah suatu cerita dalam bentuk dialog tentang konflik (pertengkaran) manusia, diproyeksikan dengan ucapan dan perbuatan dari suatu panggung kepada penonton."

Di dalam Kamus Besar Bahasa Indonesia ( 2000 ) dikatakan bahwa, "drama berarti lakon (komedi, tragedi, dan sebagainya) yang dipentaskan. Sedangkan dalam Kamus Umum Bahasa Indonesia ( 2003 : 275) dituliskan bahwa drama adalah,

a. Komposisi syair atau prosa yang diharapkan dapat menggambarkan kehidupan dan watak melalui tingkah laku/akting atau dialog yang dipentaskan;

b. Cerita atau kisah, terutama yang melibatkan konflik atau emosi, yang khusus disusun untuk pertunjukan teater;

c. Kejadian yang menyedihkan.

Sebagaimana Sumarjo dan Saini K. M (1986 : 31) berpendapat bahwa, Drama adalah karya sastra yang mengungkapkan cerita melalui dialog-dialog para tokohnya. Drama sebagai karya sebenarnya hanya bersifat sementara, sebab naskah drama ditulis sebagai dasar untuk dipentaskan. Dengan demikian, tujuan drama bukan untuk dibaca seperti orang membaca puisi atau novel. Drama yang sebenarnya adalah kalau nakah sastra tadi telah dipentaskan.

Berdasarkan uraian di atas, dapat disimpulkan bahwa drama itu merupakan hasil karya sastra yang menggambarkan kehidupan dan aktivitas manusia dengan menyajikan berbagai adegan dan dialog antara sekelompok pelakunya.

\subsection{Teknik Bermain Drama}

Rendra (2007 : 9) mengemukakan teknik bermain drama yaitu,"1) Permainan yang hidup; 2) Mendengar dan menanggapi; 3) Kejelasan ucapan; 4) Tekanan ucapan; 5) Kerasnya ucapan; 6) Membina Klimaks; 7) Bergerak dengan alasan; 8) Proyeksi; 9) Cara muncul dan keluar; 10) Timming; 11) Tempo permainan; 12) Improvisasi."

Titik fokus perhatian dan hal utama dalam bermain drama adalah aktor itu sendiri. Hal ini ditegaskan pula oleh Wiyanto (2002:57) bahwa," Hasil karya aktor melekat di tubuhnya sendiri. Bagaimana ia bemain, bergerak dan berbicara di panggung. Hasil karya seorang aktor adalah peragaan cerita. Dalam memperagakan cerita itu aktor melakukan perbuatan aktif yang disebut akting. Jadi hasil karya aktor adalah akting."

Dengan demikian dapat diambil kesimpulan bahwa kemampuan bermain drama adalah kemampuan aktor dalam menerapkan teknik bermain drama secara tepat dalam memainkan peran secara ekspresif di atas panggung. Kemampuan aktor menerapkan teknik bermain drama, seperti kemapuan menerapkan teknik permainan yang hidup, teknik mendengar dan menanggapi, teknik kejelasan ucapan, teknik tekanan ucapan, teknik kerasnya ucapan, teknik membina klimaks, teknik bergerak denagn alasan, teknik proyeksi, teknik memahami takaran, teknik timing, teknik tempo permainan, teknik improvisasi, dengan tepat diperolehnya dari hasil proses latihannya.

\section{Metode Penelitian}

Tabel Lembar Penilaian

\begin{tabular}{|c|c|c|}
\hline No. & Aspek yang dinilai & Skor \\
\hline 1. & $\begin{array}{l}\text { Kemampuan penerapan } \\
\text { teknik permainan yang } \\
\text { hidup }\end{array}$ & 10 \\
\hline 2. & $\begin{array}{l}\text { Kemampuan penerapan } \\
\text { teknik muncul dan keluar }\end{array}$ & 10 \\
\hline 3. & $\begin{array}{ll}\text { Kemampuan } & \text { penerapan } \\
\text { teknik ucapan } & \end{array}$ & 10 \\
\hline 4. & $\begin{array}{ll}\text { Kemampuan } & \text { penerapan } \\
\text { teknik tempo } & \end{array}$ & 10 \\
\hline 5. & Kemampuan & 10 \\
\hline
\end{tabular}




\begin{tabular}{|c|l|c|}
\hline & teknik timing & \\
\hline 6. & $\begin{array}{l}\text { Kemampuan penerapan } \\
\text { teknik mendengar dan } \\
\text { Menanggapi }\end{array}$ & 10 \\
\hline 7. & $\begin{array}{l}\text { Kemampuan penerapan } \\
\text { teknik proyeksi penerapan }\end{array}$ & 10 \\
\hline 8. & $\begin{array}{l}\text { Kemampuan pan } \\
\text { teknik membina Klimaks }\end{array}$ & 10 \\
\hline 9. & $\begin{array}{l}\text { Kemampuan penerapan } \\
\text { teknik bergerak dengan } \\
\text { Alasan }\end{array}$ & 10 \\
\hline 10 & $\begin{array}{l}\text { Kemampuan penerapan } \\
\text { teknik improvisasi }\end{array}$ & 100 \\
\hline & \multicolumn{2}{|c|}{ Jumlah Skor } \\
\hline
\end{tabular}

Tabel Indikator Penilaian Acuan Patokan

\begin{tabular}{|c|l|l|}
\hline Angka & Skor & \multicolumn{1}{|c|}{ Kategori } \\
\hline 4 & $\begin{array}{l}85- \\
100\end{array}$ & Sangat tinggi \\
\hline 3 & $75-84$ & Tinggi \\
\hline 2 & $60-74$ & Sedang \\
\hline 1 & $50-59$ & Rendah \\
\hline 0 & $0-49$ & $\begin{array}{l}\text { Sangat } \\
\text { rendah }\end{array}$ \\
\hline
\end{tabular}

Dalam penelitian ini, data akan dianalisis secara deskriptif yaitu berupa nilai hasil belajar mahasiswa yang dilakukan dengan mencari persentase keberhasilan belajar. Untuk mengetahui persentase kemampuan mahasiswa digunakan rumus :

$$
\mathrm{PPH}=\frac{\mathrm{B}}{\mathrm{N}} \times 100 \%
$$

(Nurkancana, $1986: 80$ )

Keterangan :

$$
\begin{array}{ll}
\mathrm{PPH} & =\text { Persentase Penilaian Hasil } \\
\mathrm{B} & =\text { Skor yang diperoleh } \\
\mathrm{N} & =\text { Skor total }
\end{array}
$$

\section{Hasil Penelitian \\ 4.1. Pre Test}

Tabel Penilaian Pre Test

\begin{tabular}{|l|l|l|l|l|l|l|l|l|l|l|l}
\hline \multirow{2}{*}{ No } & \multicolumn{10}{|c|}{ Kriteria Penilian } & \multirow{2}{*}{ Skor } \\
\cline { 2 - 10 } & $\mathbf{1}$ & $\mathbf{2}$ & $\mathbf{3}$ & $\mathbf{4}$ & $\mathbf{5}$ & $\mathbf{6}$ & $\mathbf{7}$ & $\mathbf{8}$ & $\mathbf{9}$ & $\mathbf{1}$ & \\
\hline $\mathbf{1}$ & 5 & 5 & 5 & 5 & 4 & 4 & 6 & 4 & 4 & 3 & 45 \\
\hline $\mathbf{2}$ & 5 & 5 & 4 & 4 & 5 & 5 & 4 & 4 & 4 & 4 & 44 \\
\hline $\mathbf{3}$ & 4 & 4 & 4 & 4 & 4 & 4 & 4 & 4 & 4 & 3 & 39 \\
\hline $\mathbf{4}$ & 4 & 5 & 5 & 5 & 6 & 3 & 3 & 3 & 3 & 3 & 40 \\
\hline $\mathbf{5}$ & 6 & 5 & 5 & 6 & 6 & 5 & 5 & 4 & 4 & 4 & 50 \\
\hline
\end{tabular}

\begin{tabular}{|c|c|c|c|c|c|c|c|c|c|c|c|}
\hline $\mathbf{6}$ & 6 & 6 & 6 & 6 & 6 & 5 & 5 & 5 & 5 & 4 & 54 \\
\hline $\mathbf{7}$ & 7 & 5 & 6 & 5 & 5 & 5 & 6 & 6 & 6 & 4 & 55 \\
\hline $\mathbf{8}$ & 4 & 4 & 4 & 4 & 4 & 4 & 4 & 3 & 3 & 3 & 37 \\
\hline $\mathbf{9}$ & 4 & 5 & 5 & 5 & 4 & 5 & 4 & 5 & 4 & 3 & 44 \\
\hline $\mathbf{1 0}$ & 6 & 5 & 6 & 6 & 6 & 5 & 4 & 5 & 5 & 4 & 52 \\
\hline $\mathbf{1 1}$ & 4 & 5 & 4 & 4 & 4 & 4 & 4 & 4 & 4 & 4 & 41 \\
\hline $\mathbf{1 2}$ & 4 & 4 & 4 & 4 & 4 & 4 & 4 & 5 & 5 & 4 & 42 \\
\hline $\mathbf{1 3}$ & 5 & 4 & 5 & 5 & 5 & 4 & 5 & 5 & 4 & 4 & 46 \\
\hline $\mathbf{1 4}$ & 6 & 6 & 6 & 6 & 6 & 6 & 6 & 6 & 6 & 4 & 58 \\
\hline $\mathbf{1 5}$ & 6 & 6 & 6 & 5 & 6 & 5 & 5 & 6 & 5 & 5 & 55 \\
\hline $\mathbf{1 6}$ & 5 & 7 & 7 & 7 & 6 & 5 & 4 & 5 & 5 & 4 & 55 \\
\hline $\mathbf{1 7}$ & 4 & 4 & 4 & 3 & 3 & 2 & 3 & 2 & 3 & 2 & 30 \\
\hline $\mathbf{1 8}$ & 3 & 3 & 3 & 3 & 4 & 4 & 3 & 4 & 4 & 3 & 34 \\
\hline $\mathbf{1 9}$ & 4 & 5 & 4 & 3 & 3 & 4 & 4 & 4 & 4 & 3 & 38 \\
\hline $\mathbf{2 0}$ & 6 & 6 & 6 & 5 & 6 & 6 & 6 & 6 & 6 & 5 & 58 \\
\hline & \multicolumn{10}{|c|}{ JUMLAH } \\
\hline & \multicolumn{10}{|c|}{ PPH } \\
\hline
\end{tabular}

Berdasarkan pre test dapat dijabarkan bahwa kemampuan bermain drama mahasiswa mahasiswa jurusan sastra inggris Sekolah Tinggi Ilmu Bahasa Asing Persada Bunda terutama dalam kemampuan menerapkan teknik permainan yang hidup, muncul dan keluar, ucapan, tempo, timing, mendengar dan menanggapi, proyeksi, membina klimaks, bergerak dengan alasan dan improvisasi masih perlu ditingkatkan dengan perolehan jumlah skor 917 dengan perolehan persentase perolehan hasil (PPH) kemampuan bermain drama adalah 45,85\% dengan kategori rendah.

Sesuai dengan hasil pre test yang telah dilakukan, maka perlu menerapkan model pembelajaran Role Play untuk meningkatkan kemampuan bermain drama mahasiswa jurusan sastra inggris Sekolah Tinggi Ilmu Bahasa Asing Persada Bunda.

\section{2. Post Test}

Tabel Penilaian Post Test

\begin{tabular}{|c|c|c|c|c|c|c|c|c|c|c|c|}
\hline \multirow{2}{*}{ No } & \multicolumn{10}{|c|}{ Kriteria penilian } & \multirow{2}{*}{ Skor } \\
\cline { 2 - 10 } & $\mathbf{1}$ & $\mathbf{2}$ & $\mathbf{3}$ & $\mathbf{4}$ & $\mathbf{5}$ & $\mathbf{6}$ & $\mathbf{7}$ & $\mathbf{8}$ & $\mathbf{9}$ & $\mathbf{1 0}$ & \\
\hline $\mathbf{1}$ & 7 & 8 & 7 & 7 & 8 & 8 & 8 & 7 & 7 & 7 & 74 \\
\hline $\mathbf{2}$ & 7 & 7 & 8 & 8 & 7 & 8 & 8 & 7 & 7 & 7 & 74 \\
\hline $\mathbf{3}$ & 7 & 8 & 8 & 7 & 7 & 8 & 7 & 7 & 8 & 7 & 74 \\
\hline $\mathbf{4}$ & 7 & 7 & 7 & 7 & 8 & 7 & 7 & 7 & 7 & 7 & 71 \\
\hline $\mathbf{5}$ & 8 & 9 & 7 & 9 & 9 & 8 & 9 & 9 & 8 & 8 & 84 \\
\hline $\mathbf{6}$ & 8 & 8 & 7 & 8 & 8 & 7 & 7 & 7 & 7 & 8 & 75 \\
\hline $\mathbf{7}$ & 8 & 7 & 7 & 8 & 7 & 8 & 8 & 7 & 7 & 7 & 74 \\
\hline $\mathbf{8}$ & 7 & 7 & 7 & 8 & 8 & 7 & 7 & 8 & 7 & 7 & 73 \\
\hline $\mathbf{9}$ & 7 & 8 & 7 & 7 & 7 & 8 & 7 & 7 & 7 & 7 & 72 \\
\hline $\mathbf{1 0}$ & 8 & 7 & 7 & 8 & 7 & 7 & 7 & 8 & 8 & 8 & 75 \\
\hline $\mathbf{1 1}$ & 6 & 8 & 8 & 7 & 7 & 7 & 8 & 7 & 6 & 7 & 71 \\
\hline $\mathbf{1 2}$ & 7 & 7 & 7 & 8 & 7 & 8 & 7 & 7 & 8 & 7 & 73 \\
\hline
\end{tabular}




\begin{tabular}{|c|c|c|c|c|c|c|c|c|c|c|c}
\hline $\mathbf{1 3}$ & 7 & 6 & 7 & 7 & 7 & 7 & 7 & 7 & 6 & 7 & 68 \\
\hline $\mathbf{1 4}$ & 8 & 9 & 9 & 9 & 9 & 9 & 7 & 8 & 9 & 9 & 86 \\
\hline $\mathbf{1 5}$ & 8 & 8 & 8 & 7 & 8 & 7 & 7 & 8 & 7 & 8 & 76 \\
\hline $\mathbf{1 6}$ & 7 & 9 & 8 & 7 & 7 & 8 & 6 & 7 & 8 & 7 & 74 \\
\hline $\mathbf{1 7}$ & 6 & 8 & 8 & 8 & 7 & 7 & 7 & 7 & 6 & 7 & 71 \\
\hline $\mathbf{1 8}$ & 7 & 7 & 6 & 7 & 7 & 7 & 8 & 8 & 6 & 7 & 70 \\
\hline $\mathbf{1 9}$ & 9 & 9 & 9 & 7 & 8 & 7 & 7 & 8 & 7 & 7 & 78 \\
\hline $\mathbf{2 0}$ & 9 & 9 & 9 & 9 & 9 & 8 & 8 & 9 & 9 & 9 & 88 \\
\hline \multicolumn{10}{|c|}{ PPH ULA } \\
\hline & \multicolumn{10}{|c|}{} \\
\hline
\end{tabular}

Tabel Peningkatan Hasil Belajar

Berdasarkan data post test dapat dijabarkan bahwa kemampuan bermain drama mahasiswa mahasiswa jurusan sastra inggris Sekolah Tinggi Ilmu Bahasa Asing Persada Bunda setelah menerapkan Model Pembelajaran Role Play terutama dalam kemampuan menerapkan teknik permainan yang hidup, muncul dan keluar, ucapan, tempo, timing, mendengar dan menanggapi, proyeksi, membina klimaks, bergerak dengan alasan dan improvisasi mengalami peningkatan dengan perolehan jumlah skor 1.501. Berdasarkan paparan tersebut di atas dapat dijelaskan bahwa perolehan persentase perolehan hasil (PPH) kemampuan bermain drama adalah 75,05\% dengan kategori tinggi.

Sesuai dengan hasil post test yang telah dilakukan, model pembelajaran Role Play dapat meningkatkan kemampuan bermain drama mahasiswa jurusan sastra inggris Sekolah Tinggi Ilmu Bahasa Asing Persada Bunda.

\begin{tabular}{|c|c|c|c|}
\hline No & $\begin{array}{l}\text { Pre } \\
\text { Test }\end{array}$ & $\begin{array}{l}\text { Post } \\
\text { Test }\end{array}$ & $\begin{array}{c}\text { Pening } \\
\text { katan }\end{array}$ \\
\hline 1 & 45 & 74 & 29 \\
\hline 2 & 44 & 74 & 30 \\
\hline 3 & 39 & 74 & 35 \\
\hline 4 & 40 & 71 & 31 \\
\hline 5 & 50 & 84 & 34 \\
\hline 6 & 54 & 75 & 21 \\
\hline 7 & 55 & 74 & 19 \\
\hline 8 & 37 & 73 & 36 \\
\hline 9 & 44 & 72 & 28 \\
\hline 10 & 52 & 75 & 23 \\
\hline 11 & 41 & 71 & 30 \\
\hline 12 & 42 & 73 & 31 \\
\hline 13 & 46 & 68 & 22 \\
\hline 14 & 58 & 86 & 28 \\
\hline 15 & 55 & 76 & 21 \\
\hline 16 & 55 & 74 & 19 \\
\hline 17 & 30 & 71 & 41 \\
\hline 18 & 34 & 70 & 36 \\
\hline 19 & 38 & 78 & 40 \\
\hline 20 & 58 & 88 & 30 \\
\hline Jumlah & 917 & 1501 & 584 \\
\hline PPH & $45,85 \%$ & $75,05 \%$ & $29,20 \%$ \\
\hline
\end{tabular}

Dari tabel di atas dapat diketahui bahwa terdapat peningkatan hasil belajar mahasiswa dari pre test ke post tes dengan PPH sebesar 29,20\%. Peningkatan ini dapat dilihat dari aktivitas belajar mahasiswa selama proses belajar mengajar berlangsung. Dengan demikian penerapan model pembelajaran role play membantu meningkatkan kemampuan bermain drama mahasiswa jurusan sastra inggris Sekolah Tinggi Ilmu Bahasa Asing Persada Bunda. 


\section{Kesimpulan dan Saran \\ 5.1 Kesimpulan}

Berdasarkan hasil penelitian ini, dapat disimpulkan bahwa model pembelajaran Role Play dapat meningkatkan kemampuan bermain drama mahasiswa jurusan sastra inggris Sekolah Tinggi Ilmu Bahasa Asing Persada Bunda.

\subsection{Saran}

Semoga Penelitian ini dapat memperluas khasanah keilmuan nusantara baik dibidang pengajaran drama maupun seni lainnya yang berhubungan dengan seni drama. Diharapkan penelitian ini dapat menjadi referensi untuk penelitian-penelitian selanjutnya.

\section{Daftar Pustaka}

Depdikbud. 1985. Kamus Istilah Seni Drama. Jakarta : Pusat Pembinaan dan Pengembangan Depdikbud
Depdiknas. 2003. Kamus Besar Bahasa Indonesia. Jakarta : Balai Pustaka

Prasmadji, R. H. 1984. Teknik Menyutradarai Darama Konvensional. Jakarta : Balai Pustaka

Rendra, W. S. Drama Untuk Remaja. Jakarta : Burung Merak Press

Sani, Asrul. 1980. Persiapan Sang Aktor (Constantin Stanyslavsky). Jakarta : Bastela Pranindo

Sumarjo, Jacob dan Saini, KM. 1986. Apresiasi Kesusasteraan. Jakarta : Gramedia Pustaka Umum

Wiyanto, Asul. 2002. Terampil Bermain Drama. Jakarta : Gramedia Widiasarana Indonesia

Uno, B. Hamzah. 2002. Model Pembelajaran. Jakarta : Bumi Aksara 